\title{
Effect of exogenous phytase on degradation of inositol phosphate in dairy cows
}

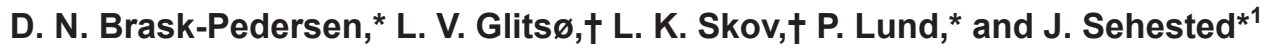 \\ *Department of Animal Science, Faculty of Science and Technology, Aarhus University, AU Foulum, PO Box 50, 8830 Tjele, Denmark \\ †R\&D, Novozymes A/S, DK-2880 Bagsvaerd, Denmark
}

\begin{abstract}
The effect of exogenous phytase on inositol phosphate degradation in the rumen of dairy cows was investigated in a $4 \times 4$ Latin square design. Four lactating Danish Holstein cows fitted with ruminal, duodenal, and ileal cannulas were offered a total mixed ration (TMR) with a high content of inositol phosphate and supplemented with 1 of 4 concentrations of phytase [none, low, medium, or high, corresponding to 23, 2,023, 3,982, and 6,015 phytase units/kg of dry matter (DM)]. Exogenous phytase lead to a higher rumen pool of phytase. Inositol phosphate content in digesta samples from rumen, duodenum, ileum, and feces was almost entirely composed of myo-inositol hexakisphosphate $\left(\mathrm{InsP}_{6}\right)$, indicating that degradation of this compound is the rate-limiting step in inositol phosphate degradation in the digestive tract. Ruminal and total-tract degradations of $\mathrm{InsP}_{6}$ were higher when exogenous phytase was added to the TMR. Degradation of $\operatorname{InsP}_{6}$ occurred mainly before the duodenum. The ruminal degradability of $\operatorname{InsP}_{6}$ was increased with increasing dietary concentrations of phytase: $86.4,93.7,94.5$, and $96.3 \%$ for none, low, medium, or high, respectively. A comparison of the $\operatorname{InsP}_{6}$ content in individual feedstuffs and in samples of the TMR revealed that the exogenous phytase started degrading the inositol phosphate when feeds and phytase were mixed, and thus the $\operatorname{InsP}_{6}$ phosphorus $\left(\operatorname{InsP}_{6}-\mathrm{P}\right)$ content in the TMR was found to decrease with higher doses of phytase $(1.69,1.51,1.39$, and $1.25 \mathrm{~g} / \mathrm{kg}$ of DM for the none, low, medium, and high phytase doses, respectively). It was not possible to distinguish between the degradation of inositol phosphate occurring in the TMR and in the rumen. Exogenous phytase had no effect on total $\mathrm{P}$ intake or flow of total $\mathrm{P}$ to the duodenum and ileum, whereas exogenous phytase increased flow of microbial $\mathrm{P}$ to the duodenum and total fecal $\mathrm{P}$ excretion. None of the investigated rumen variables ( $\mathrm{pH}$, degradability of neutral detergent fiber, and ru-
\end{abstract}

Received December 20, 2011.

Accepted November 16, 2012

${ }^{1}$ Corresponding author: jakob.sehested@agrsci.dk men kinetics for neutral detergent fiber) were affected by treatment. Rumen and total-tract degradations of inositol phosphate were increased when exogenous phytase was added to the TMR, which offers the potential for reducing $\mathrm{P}$ excretion through reduced dietary $\mathrm{P}$.

Key words: inositol phosphate, phytase, phosphorus availability, cattle

\section{INTRODUCTION}

Phytate, the salt of phytic acid (myo-inositol hexakisphosphate, $\mathbf{I n s P}_{\mathbf{6}}$ ), is the main storage form of $\mathrm{P}$ in cereals, legumes, and oilseeds (Nelson et al., 1968; Godoy et al., 2005), and the $\mathrm{P}$ associated with $\operatorname{InsP}_{6}$ $\left(\right.$ InsP $\left._{6}-\mathbf{P}\right)$ can constitute 60 to $80 \%$ of the total P content in cereal grains and 35 to $50 \%$ in byproducts such as soybean meal and rapeseed cake (Eeckhout and De Paepe, 1994; Viveros et al., 2000). Forages have a much lower content of InsP $\mathrm{P}_{6}$, and only traces have been found in alfalfa and different grasses (Nelson et al., 1976), as most forages merely consist of stems and leaves. The enzyme phytase catalyzes the hydrolysis of $\mathrm{InsP}_{6}$ and produces lower inositol phosphates: myo-inositol pentakis-, tetrakis-, tris-, bis-, and monophosphates ( $\mathbf{I n s P}_{5}$ to InsP $_{1}$ ) (Irving, 1980; Wodzinski and Ullah, 1996). Previously, inositol phosphate $\mathrm{P}$ was considered to be fully available to ruminants because of the microbial phytase activity in the rumen (Clark et al., 1986; Morse et al., 1992a). However, studies have shown that ruminal degradation of $\operatorname{InsP}_{6}$ is reduced by the processing of feedstuffs by means of, for example, heat or formaldehyde treatment (Konishi et al., 1999; Park et al., 1999; Bravo et al., 2000). Furthermore, recent studies have indicated that the ruminal degradation of $\mathrm{InsP}_{6}$ is not complete and is increased by supplementation with exogenous phytase (Kincaid et al., 2005; Sehested and Lund, 2007). Other recent studies verify the potential to reduce the excretion or improve the digestibility of $\mathrm{P}$ in goats, dry cows, and lactating cows using exogenous phytase (Bravo et al., 2002; Knowlton et al., 2005, 2007).

The use of feeds rich in inositol phosphate such as grains and oilseed meals is substantial in cattle produc- 
tion, and exogenous phytase might play a significant role in securing the supply of available $\mathrm{P}$ to ruminal microbes and animals. Improved availability of feed $\mathrm{P}$ would make it possible to meet the needs of the microbes and the animal with reduced $\mathrm{P}$ intake, which in turn can decrease the $\mathrm{P}$ content of livestock manure. The un-utilized inositol phosphate $\mathrm{P}$ and inorganic $\mathrm{P}$ are excreted with manure and contribute to environmental problems by eutrophication of water resources (Sharpley and Winthers, 1994). In several studies, intake and excretion of $\mathrm{P}$ in cattle have been found to be closely related (Morse et al., 1992b; Wu et al., 2000; Dou et al., 2003), and therefore even small improvements in the availability of feed $\mathrm{P}$ will improve the whole-farm $\mathrm{P}$ balance and decrease the potential for $\mathrm{P}$ run-offs from farms (Knowlton et al., 2004).

Exogenous phytase is extensively used as a feed additive in monogastric animals, but to our knowledge, no commercial phytase has been developed specifically for ruminant application. An initial in vitro study simulating ruminal conditions was therefore performed to find a suitable phytase for ruminants (Brask-Pedersen et al., 2011), and the most efficient phytase was used in the present study.

The objective of the present experiment was to investigate the effect of exogenous phytase on the degradation of inositol phosphate in dairy cows. A second objective was to determine the relationship between dose and effect, to form a basis for future recommendations for the application of phytase for dairy cows.

\section{MATERIALS AND METHODS}

\section{Animals and Feeding}

The present experiment complied with the guidelines of the Danish Ministry of Justice with respect to animal experimentation and care of animals under study.

Four lactating Danish Holstein dairy cows varying in weight from 501 to $787 \mathrm{~kg}$ were used in the study. Two cows were in second lactation, 1 was in fourth lactation, and 1 was in its first lactation. Cows were $221 \pm 90 \mathrm{~d}$ postpartum at the beginning of the experiment and were fitted with ruminal (\#1C; Bar Diamond Inc., Parma, ID), duodenal (open T-piece placed $60 \mathrm{~cm}$ caudal to the pylorus), and ileal (open T-piece placed $20 \mathrm{~cm}$ cranial to the cecum) cannulas. Chromic oxide $\left(\mathrm{Cr}_{2} \mathrm{O}_{3}\right)$ was used as the intestinal digesta flow marker by administering $10 \mathrm{~g}$ via the rumen cannula at each feeding (0830 and $1730 \mathrm{~h}$ ). Cows were housed in tie stalls with rubber mats, had free access to water, and were milked twice daily at 0500 and $1700 \mathrm{~h}$.
The experiment was based on a $4 \times 4$ Latin square design with 4 cows, 4 treatments, and 4 periods. The 4 treatments consisted of 4 levels of microbial phytase added to the TMR (none, low, medium, or high, which aimed to correspond to $0,1,200,2,400$, and 3,600 phytase units (FTU) $/ \mathrm{kg}$ of feed or equal to 0, 2,122, 4,245 , and $6,367 \mathrm{FTU} / \mathrm{kg}$ of DM). Based on the phytase content in the individual feeds and the addition of microbial phytase, the obtained (analyzed) phytase contents in the 4 treatments were $23,2,023,3,982$, and $6,015 \mathrm{FTU} / \mathrm{kg}$ of $\mathrm{DM}$ for the treatments none, low, medium, and high, respectively. One FTU is defined as the amount of enzyme that liberates $1 \mu \mathrm{mol}$ of inorganic phosphate per min from a $0.0051 \mathrm{M}$ Na-phytate solution at $\mathrm{pH} 5.5$ and $37^{\circ} \mathrm{C}$ (Engelen et al., 1994). The microbial 6-phytase used in the present study was a histidine acid phosphatase phytase expressed by a recombinant strain of Aspergillus oryzae supplied by Novozymes A/S (Bagsvaerd, Denmark). The phytase was selected among 4 candidates on the basis of in vitro studies (Brask-Pedersen et al., 2011).

Cows were fed ad libitum with a TMR. The phytase was mixed with the rapeseed cake before it was added to the rations. The TMR (g/ $\mathrm{kg}$ of DM) was composed of corn silage (167), clover grass silage (263), rapeseed cake (201), dried beet pulp (297), corn feed meal (24), and cane molasses (48). The chemical composition of the feedstuffs and the TMR is listed in Table 1.

\section{Sampling}

After an adaptation period of $14 \mathrm{~d}, 12$ samples of ruminal fluid, duodenal and ileal contents, feces, and urine were obtained at 6 - or 8 -h intervals over 5 consecutive days. The collection procedure was arranged to give representative samples of the diurnal flow (i.e., every second hour of the 24-h day). Samples from the duodenum and ileum were collected in tube-formed plastic bags attached to the cannula with a plastic knee. Feces and urine were collected in cups. Duodenal and ileal digesta, feces, and urine were stored at $-20^{\circ} \mathrm{C}$ and all were pooled within cow and period. Ruminal fluid was obtained from the ventral rumen compartment and strained through 2 layers of cheesecloth. The $\mathrm{pH}$ was determined immediately using a PHC-2412 combination electrode (Radiometer, Brønshøj, Denmark) connected to a RHM-220 pH measuring device (Radiometer), which was autocalibrated using standard buffers of $\mathrm{pH} 4$ and 7 before each sampling. Afterward, the rumen fluid was stored at $-20^{\circ} \mathrm{C}$ until analysis. The amounts of feed offered and refused were recorded and sampled at each sampling day and then pooled within treatment and period. Individual feeds were sampled 
Table 1. Chemical composition of feedstuffs used to formulate the feed ration

\begin{tabular}{|c|c|c|c|c|c|c|c|}
\hline Item & \multicolumn{7}{|c|}{ Feedstuff } \\
\hline $\mathrm{CP}(\mathrm{g} / \mathrm{kg}$ of $\mathrm{DM})$ & 8.1 & 311.2 & 96.7 & 44.3 & 209.6 & 93.0 & 164.5 \\
\hline Crude fat $(\mathrm{g} / \mathrm{kg}$ of $\mathrm{DM})$ & 0.0 & 135.1 & 6.7 & 0.0 & 34.8 & 32.9 & 44.0 \\
\hline $\mathrm{NDF}(\mathrm{g} / \mathrm{kg}$ of $\mathrm{DM})$ & 4.0 & 262.5 & 409.3 & 0.0 & 395.8 & 399.9 & 346.8 \\
\hline $\mathrm{P}(\mathrm{g} / \mathrm{kg}$ of $\mathrm{DM})$ & 0.0 & 10.9 & 0.9 & 0.4 & 3.8 & 2.2 & 3.8 \\
\hline InsP-P ${ }^{4}(\mathrm{~g} / \mathrm{kg}$ of $\mathrm{DM})$ & 0.0 & 8.1 & 0.1 & 0.0 & 0.0 & 0.0 & 1.7 \\
\hline Phytase $(\mathrm{FTU} / \mathrm{kg} \text { of DM })^{5}$ & 0.0 & 59.8 & 6.9 & 67.3 & 82.3 & 31.4 & - \\
\hline $\mathrm{NE}_{\mathrm{L}}(\mathrm{MJ} / \mathrm{kg}$ of $\mathrm{DM})$ & 9.4 & 9.6 & 8.0 & 7.2 & 6.3 & 7.2 & 7.7 \\
\hline
\end{tabular}

${ }^{1}$ Values represent duplicate assays of pooled samples from subsamples from each period.

${ }^{2}$ Values represent duplicate assays of 4 samples, 1 sample per period.

${ }^{3}$ In vitro OM digestibility.

${ }^{4}$ Phosphorus associated with inositol phosphate.

${ }^{5}$ Endogenous phytase in the feedstuff. One phytase unit (FTU) is the amount of enzyme that liberates $1 \mu$ mol of inorganic phosphate per minute from $0.0051 \mathrm{M}$ Na-phytate at $\mathrm{pH} 5.5$ and $37^{\circ} \mathrm{C}$ (Engelen et al., 1994).

before mixing, and samples of TMR were sampled 2 to $3 \mathrm{~h}$ after mixing.

On d 2 (evening) and d 3 (morning) of the sampling period, the milk yield was recorded and milk samples were collected. Afterward, the samples were pooled within cow and period.

On d 3 (1230 h) of each sampling period, rumen fluid was collected from individual cows for analyses of microbial $\mathrm{P}$ and purines. The rumen fluid was strained through 6 layers of cheesecloth, transferred to three $250-\mathrm{mL}$ centrifuge tubes, and centrifuged at $409 \times \mathrm{g}$ at $3{ }^{\circ} \mathrm{C}$ for $2 \times 20 \mathrm{~min}$. The supernatant was then centrifuged at $17,300 \times g$ at $3^{\circ} \mathrm{C}$ for $2 \times 20 \mathrm{~min}$. The pelleted fractions were frozen $\left(-20^{\circ} \mathrm{C}\right)$ and freeze-dried.

On d 1 and $5(0945 \mathrm{~h})$ of the sampling period, blood samples were taken from the tail vein of cows with evacuated tubes containing EDTA. The samples were immediately placed on ice until centrifugation $(2,200$ $\times g$ for $20 \mathrm{~min}$ ), and plasma was harvested and stored at $-20^{\circ} \mathrm{C}$ until analysis. The average of the 2 samples from each cow in each period was used in the statistical analysis.

On the final day of each period $(1230 \mathrm{~h})$, rumen evacuations were performed on all 4 cows. The rumen contents were collected in sieve baskets hanging in an iron stand in a circular tub. The container allowed liquid to pass into the tub, leaving the solid fraction in the container. With each evacuation, a sample was made up of subsamples of rumen liquid and solid fraction proportional to the weight of each fraction.

Feed, duodenal, ileal, feces, and rumen samples were all frozen $\left(-20{ }^{\circ} \mathrm{C}\right)$, freeze-dried, and ground using a hammer mill through a 1-mm screen before chemical analysis.

\section{Laboratory Analysis}

Dry matter content was determined by drying at $60^{\circ} \mathrm{C}$ for $48 \mathrm{~h}$ (forages), at $100^{\circ} \mathrm{C}$ for $48 \mathrm{~h}$ (concentrates), or in vacuum at $85^{\circ} \mathrm{C}$ for $4 \mathrm{~h}$ (cane molasses). Ash content was determined by combustion performed at $525^{\circ} \mathrm{C}$ for $6 \mathrm{~h}$ (AOAC, 1990). Crude protein was calculated based on the amount of total N, which was determined using the Dumas method (Hansen, 1989). Crude fat was determined in a Soxhlet apparatus with petroleum ether extraction after $3 M \mathrm{HCl}$ hydrolysis (Stoldt, 1952). In vitro digestibility of $\mathrm{OM}$ in forage was determined by anaerobic incubation in diluted rumen fluid, followed by incubation of the insoluble material with pepsin$\mathrm{HCl}$ solution (Tilley and Terry, 1963). In concentrates, determination of in vitro digestibility of $\mathrm{OM}$ was made by treating the samples with pepsin- $\mathrm{HCl}$ solution and subsequent incubation with enzymes (Weisbjerg and Hvelplund, 1993). Content of NDF was determined using the Fibertec M6 system (Foss Analytical, Hillerød, Denmark), using heat-stable amylase to remove starch and sodium sulfite to remove proteinaceous material, followed by neutral detergent boiling (Mertens, 2002). Calcium in the feed was determined by atomic absorption spectrophotometry (Atomic Absorption System SP9, Pye Unicam Ltd., Cambridge, UK). Samples of feed, ruminal, duodenal and ileal contents, feces, milk, and microbes were degraded by dry ashing $\left(450^{\circ} \mathrm{C}\right.$ for $3 \mathrm{~h}$ ) and assayed for concentration of total $\mathrm{P}$ by the ammonium vanadate method (Stuffins, 1967). Samples of microbes and duodenal content were hydrolyzed with perchloric acid followed by precipitation with silver nitrate, and content of total purines was determined spectrophotometrically (Zinn and Owens, 1986). Urine 
and plasma samples were analyzed for inorganic P using an ammonium molybdate-based kit (Cobas PHOS kit, Roche Diagnostics GmbH, Mannheim, Germany) on a Roche/Hitachi 912 auto analyzer (Roche Diagnostics $\mathrm{GmbH}$ ). Content of $\mathrm{Cr}_{2} \mathrm{O}_{3}$ in digesta and feces was determined colorimetrically after oxidation to chromate (Schürch et al., 1950). Determination of phytase activity in the feedstuffs followed the procedure of Engelen et al. (1994). Phytase activity was determined in rumen samples and expressed in FTU adapted from the definition of Engelen et al. (1994). In brief, rumen samples were thawed and immediately diluted in Na-acetate buffer (0.25 M; $5 \mathrm{mM} \mathrm{Ca}{ }^{2+} ; 0.01 \%$ Tween, $\left.\mathrm{pH} 5.5\right)$. The diluted samples were mixed with Na-phytate to give a final concentration of $5 \mathrm{~m} M$ and incubated for 30 min $\left(40^{\circ} \mathrm{C}, \mathrm{pH} 5.5\right)$. Hydrochloric acid $(1 M)$ was added to inactivate the enzyme, and the samples were diluted before quantification of phosphate (either from the sample background or from degradation of inositol phosphate) using malachite green dye and molybdate, which forms a stable, colored complex specifically with inorganic phosphate (Motomizu et al., 1983). The color reagent comprised $57 \%$ reagent A (28 $\mathrm{mM}$ ammonium heptamolybdate, $2.8 \mathrm{M}$ sulfuric acid) and $43 \%$ reagent B (0.76 m M malachite green, $0.35 \%$ polyvinyl alcohol). The absorbance at $610 \mathrm{~nm}$ was measured and compared with a phosphate standard curve. For a separate set of samples, the $\mathrm{HCl}$ was added before the substrate to avoid inositol phosphate hydrolysis and instead quantify the level of background phosphate in the sample to correct the ordinary samples for the background content. In a pretrial, it was confirmed that the recovery of graded levels of phytase was not impaired by the presence of rumen fluid. Recoveries were 90 to $110 \%$ of the amount of phytase activity added to rumen fluid. Inositol phosphates ( $\mathrm{InsP}_{6}$-InsP $\left.\mathrm{In}_{3}\right)$ in feed raw material, and freeze-dried TMR and content from the duodenum, ileum, and feces were analyzed using a modification of the method as described previously (Pontoppidan et al., 2007; Brask-Pedersen et al., 2011). The inositol phosphates were extracted from the samples following the principles of Carlsson et al. (2001). In brief, $0.5 \mathrm{~g}$ of each sample was incubated with $10 \mathrm{~mL}$ of $0.5 \mathrm{M} \mathrm{HCl}$ and mixed $(500 \mathrm{rpm})$ for $2 \mathrm{~h}$ at $22^{\circ} \mathrm{C}$. The samples were then frozen and kept at $-18^{\circ} \mathrm{C}$ for a minimum of $24 \mathrm{~h}$; after thawing, incubation was continued for $1 \mathrm{~h}$ at $22^{\circ} \mathrm{C}$ with mixing $(500 \mathrm{rpm})$. Subsequently, the samples were centrifuged $\left(14,000 \times g, 0^{\circ} \mathrm{C}, 10 \mathrm{~min}\right)$, and a sample $(500 \mu \mathrm{L})$ of the extract supernatants was placed in ultracentrifugal filter devices (Microcon YM-30, Millipore, Billerica, MA) and filtered by centrifugation $\left(12,000 \times g, 0^{\circ} \mathrm{C}, 30 \mathrm{~min}\right)$. Filtered supernatants were analyzed undiluted by high-performance ion chromatography (HPIC; Dionex Corp., Sunnyvale, CA), and inositol phosphates $\left(\operatorname{InsP}_{6}-\mathrm{InsP}_{3}\right)$ were detected after postcolumn reaction with $0.1 \% \mathrm{Fe}\left(\mathrm{NO}_{3}\right)_{3} \cdot 9 \mathrm{H}_{2} \mathrm{O}$ in a $2 \%$ solution of $\mathrm{HClO}_{4}$ by UV absorbance at $290 \mathrm{~nm}$. A reference sample for the identification of peaks was prepared by dissolving $0.5 \mathrm{~g}$ of phytic acid dodecasodium salt hydrate in $50 \mathrm{~mL}$ of $0.5 \mathrm{M} \mathrm{HCl}$. The solution was autoclaved for $1 \mathrm{~h}$ at $124^{\circ} \mathrm{C}$. Before analysis, the hydrolysate was diluted 3 times in water. Peaks were quantified according to an $\operatorname{InsP}_{6}$ standard curve. The amounts of $\operatorname{InsP}_{3}, \mathrm{InsP}_{4}$, and $\mathrm{InsP}_{5}$ were estimated in the present study using the theoretical correction factors of $2(6 / 3), 1.5(6 / 4)$, and $1.2(6 / 5)$, respectively. Results were calculated on the basis of $\mathrm{P}$ to express, for example, the amount of $\mathrm{P}$ associated with $\mathrm{InsP}_{6}\left(\mathrm{InsP}_{6^{-}}\right.$ $\mathrm{P}$ ). Because the level of inositol phosphates (which were almost entirely composed of $\operatorname{InsP}_{6}$ in all digesta samples) was very low in the ruminal and duodenal samples, the extracts of these samples were spiked with a known amount of $\operatorname{InsP}_{6}$ before the HPIC analysis. This was done to improve chromatographic detection and quantification, and the content of InsP6 in these samples was calculated by subtracting the level of $\operatorname{Ins}_{6}$ in the aqueous control samples, which only contained the spiked amount of $\operatorname{InsP}_{6}$. A subset of digesta samples was analyzed by a slightly different method (Blaabjerg et al., 2010), and comparable results were obtained. For both HPIC inositol phosphate methods, the recovery of $\mathrm{InsP}_{6}$ spiked into digesta samples of human and porcine origin has been investigated and was found to be in the range of 75 to $124 \%$ (Skoglund et al., 1997; Blaabjerg et al., 2010). We also tested the extraction method applied in the present study by spiking $\operatorname{InsP}_{6}$ into a dairy cow fecal sample and confirmed that the recovery in the extract was in the range of 92 to $114 \%$.

\section{Calculations}

Flows of nutrients to the duodenum and ileum, and content of nutrients in feces were calculated using $\mathrm{Cr}_{2} \mathrm{O}_{3}$ as marker. Duodenal flow of microbial $\mathrm{P}$ was determined based on the purine:P ratio in ruminal microbes and purine flow at the duodenum.

Apparent ruminal degradation of nutrients (e.g., $\mathrm{InsP}_{6}$ ) was calculated as the difference between daily intake and duodenal flow in proportion to the daily intake. Parameters for degradation (fractional rate of degradation, $\mathbf{k}_{\mathrm{d}} ; \mathrm{h}^{-1}$ ), passage (fractional rate of passage, $\mathbf{k}_{\mathbf{p}} ; \mathrm{h}^{-1}$ ), and mean retention time (MRT; $\mathrm{h}$ ) in the rumen were calculated based on the one-compartment model (Allen and Mertens, 1988).

\section{Statistical Analysis}

The data were analyzed with a linear normal model:

$$
\mathrm{Y}_{\mathrm{ijk}}=\mu+\mathrm{C}_{\mathrm{i}}+\mathrm{P}_{\mathrm{j}}+\mathrm{T}_{\mathrm{k}}+\varepsilon_{\mathrm{ijk}},
$$


where $Y_{i j k}$ denotes the dependent variable, $\mu$ is the overall mean, $\mathrm{C}_{\mathrm{i}}(\mathrm{i}=1,2,3,4)$ is the effect of cow, $\mathrm{P}_{\mathrm{j}}(\mathrm{j}=1,2,3,4)$ is the effect of period, and $\mathrm{T}_{\mathrm{k}}(\mathrm{k}=$ none, low, medium, high) is the effect of treatment. The $\varepsilon_{\mathrm{ijk}}$ are the independent normally distributed residual errors. Two families of hypothesis tests are provided: (1) tests of pair-wise differences and (2) tests of linear and quadratic contrasts. These 2 families are not independent and the second family is only provided as an informal analysis of the corresponding contrasts, and readers should consider only the comparisons or the contrasts and not both. Similar to Fisher's least significant difference procedure (Snedecor and Cochran, 1967), preplanned pair-wise comparison contrasts and orthogonal linear and quadratic contrasts of treatment effects were considered only when the overall $F$-test of the treatment effect was significant at $P<0.05$. Contrasts were declared significant when $P<0.05$, and data are presented as least squares of means and associated standard error of the means (SEM). The analysis was performed with the GLM procedure of the SAS software system for Windows (version 9.2, SAS Institute Inc., Cary, NC).

\section{RESULTS}

\section{DMI and Milk Production}

Dry matter intake was unaffected by treatment (19.3, $18.9,18.9$, and $18.6 \mathrm{~kg} / \mathrm{d}$ for none, low, medium, and high phytase doses). Milk yield and composition were unaffected by treatment. Intake of various nutrients was not affected by treatment.

\section{Intake and Degradation of Inositol Phosphate}

Cows were fed a TMR high in inositol phosphate, and $44 \%$ of the total $\mathrm{P}$ in the control TMR was pres- ent as inositol phosphate P. In the TMR, total inositol phosphate $\mathrm{P}$ (InsP-P $=\mathrm{Ins}_{6} \mathrm{P}-\mathrm{P}+\mathrm{InsP}_{5}-\mathrm{P}+\mathrm{InsP}_{4}-\mathrm{P}+$ $\left.\mathrm{InsP}_{3}-\mathrm{P}\right)$ and $\mathrm{InsP}_{6}-\mathrm{P}$ decreased, and $\mathrm{InsP}_{5}-\mathrm{P}$, InsP ${ }_{4}-\mathrm{P}$, and $\mathrm{InsP}_{3}-\mathrm{P}$ increased with increasing doses of phytase (Table 2$)$. The InsP-P was thus lower $(P=0.01)$ in the TMR containing exogenous phytase compared with the diet containing no phytase, which indicates that the phytase initiated the degradation of inositol phosphates in the TMR already in the trough. When comparing the intake of $\operatorname{InsP}_{6}-\mathrm{P}$ calculated on the basis of the analyzed content in the individual feedstuffs, we found no effect of treatment and, on average, cows ingested 27.3 $\pm 0.3 \mathrm{~g}$ of $\mathrm{P} / \mathrm{d}$ from $\operatorname{Ins}_{6}$ (Table 3 ). However, when intake of $\mathrm{P}$ from $\mathrm{InsP}_{6}$ was based on analyses of TMR, we found linear and quadratic effects of treatment, and $\mathrm{Ins}_{6}-\mathrm{P}$ intake decreased with increasing doses of phytase. The degradation of $\operatorname{InsP}_{6}$ continued in the rumen, as the contents of $\operatorname{InsP}_{6}-\mathrm{P}$ were lower in the duodenum samples in animals fed phytase.

Inositol phosphate content in digesta samples from rumen, duodenum, ileum, and feces was almost entirely composed of $\mathrm{InsP}_{6}$, indicating that degradation of this compound is the rate-limiting step in inositol phosphate degradation in the digestive tract. The daily duodenal, ileal, and fecal flows of $\operatorname{InsP}_{6}-\mathrm{P}$ were all lower $(P<$ 0.001 ) with exogenous phytase (Table 3 ), and the flows were also lower with the high dose than with the low and medium doses. Phytase increased rumen degradability of $\operatorname{InsP}_{6}(P<0.001)$, and the high dose resulted in a higher rumen degradability of $\operatorname{InsP}_{6}$ compared with the low and medium doses. In contrast, the rumen pool of $\mathrm{InsP}_{6}-\mathrm{P}$ was not affected by treatment, and neither were $\mathrm{k}_{\mathrm{d}}$ and MRT for InsP $\mathrm{P}_{6} \mathrm{P}$ (Table 3 ).

The addition of exogenous phytase resulted in a higher pool of phytase in the rumen $(152,456,490$, and $670 \mathrm{FTU}$ for treatments none, low, medium, and high, respectively, $P=0.027)$. However, no differences were found between the low, medium, and high phytase

Table 2. Content ( $\mathrm{g} / \mathrm{kg}$ of $\mathrm{DM})$ of phosphate associated with total inositol phosphate (InsP-P), myo-inositol hexakisphosphate (InsP ${ }_{6}$-P), pentakisphosphate $\left(\operatorname{InsP}_{5}-\mathrm{P}\right)$, tetrakisphosphate $\left(\operatorname{InsP}_{4}-\mathrm{P}\right)$, and trisphosphate $\left(\operatorname{InsP}_{3}-\mathrm{P}\right)$ in the TMR, depending on treatment

\begin{tabular}{|c|c|c|c|c|c|c|c|c|}
\hline Item & \multicolumn{4}{|c|}{ Treatment $^{1}$} & SEM & $\frac{P \text {-value }}{2}$ & \multicolumn{2}{|c|}{ Contrast $^{3}$ ( $P$-value $)$} \\
\hline InsP-P & $1.69^{\mathrm{a}}$ & $1.51^{\mathrm{ab}}$ & $1.39^{\mathrm{b}}$ & $1.25^{\mathrm{b}}$ & 0.079 & 0.036 & 0.007 & NS \\
\hline $\mathrm{InsP}_{5}-\mathrm{P}$ & $0.33^{\mathrm{a}}$ & $0.46^{\mathrm{bc}}$ & $0.43^{\mathrm{b}}$ & $0.38^{\mathrm{ab}}$ & 0.016 & 0.005 & NS & 0.002 \\
\hline $\mathrm{InsP}_{4}-\mathrm{P}$ & $0.00^{\mathrm{a}}$ & $0.05^{\mathrm{ab}}$ & $0.09^{\mathrm{b}}$ & $0.11^{\mathrm{b}}$ & 0.020 & 0.04 & 0.007 & NS \\
\hline $\operatorname{InsP}_{3}-\mathrm{P}$ & 0.00 & 0.00 & 0.04 & 0.04 & 0.024 & NS & - & - \\
\hline
\end{tabular}

\footnotetext{
${ }^{a-d}$ Means within a row with different superscripts differ $(P<0.05)$; NS when $P>0.10$.

${ }^{1}$ Treatments: 23, 2,023, 3,982, and 6,015 phytasre units (FTU)/kg of DM for none, low, medium, and high. One FTU is the amount of enzyme that liberates $1 \mu \mathrm{mol}$ of inorganic phosphate per minute from $0.0051 \mathrm{M}$ Na-phytate at $\mathrm{pH} 5.5$ and $37^{\circ} \mathrm{C}$ (Engelen et al., 1994).

${ }^{2}$ Fixed effect of treatment.

${ }^{3}$ Linear and quadric orthogonal polynomial contrasts of treatment. Readers should consider only the pairwise comparisons or the linear and quadratic contrasts and not both.
} 
Table 3. Effect of phytase doses on daily flows of myo-inositol hexakisphosphate phosphorus $\left(\mathrm{InsP}_{6}-\mathrm{P}\right)$, total and ruminal degradability of InsP ${ }_{6}$, and rumen kinetics for $\mathrm{InsP}_{6}-\mathrm{P}$

\begin{tabular}{|c|c|c|c|c|c|c|c|c|}
\hline \multirow[b]{2}{*}{ Item } & \multicolumn{4}{|c|}{ Treatment $^{1}$} & \multirow[b]{2}{*}{ SEM } & \multirow{2}{*}{$\frac{P \text {-value }}{2}$} & \multicolumn{2}{|c|}{ Contrast $^{3}(P$-value $)$} \\
\hline & None & Low & Medium & High & & & Lin & Quad \\
\hline \multicolumn{9}{|l|}{ Flow } \\
\hline \multicolumn{6}{|l|}{ Intake $(\mathrm{g} / \mathrm{d})$} & NS & - & - \\
\hline $\begin{array}{l}\text { TMR }^{5} \\
\text { TMeds }^{2}\end{array}$ & $\begin{array}{l}21.0 \\
26.2\end{array}$ & $\begin{array}{l}21.4 \\
18.8\end{array}$ & $\begin{array}{l}21.0 \\
15.8\end{array}$ & $\begin{array}{l}26.9 \\
13.4\end{array}$ & $\begin{array}{l}0.62 \\
0.96\end{array}$ & $<0.001$ & $<\overline{0.001}$ & $\overline{0.04}$ \\
\hline Duodenum (g/d) & $3.8^{\mathrm{a}}$ & $1.7^{\mathrm{b}}$ & $1.5^{\mathrm{b}}$ & $1.0^{\mathrm{c}}$ & 0.15 & $<0.001$ & $<0.001$ & 0.003 \\
\hline \multicolumn{9}{|l|}{ Degradability } \\
\hline Rumen (\%) & $86.4^{\mathrm{a}}$ & $93.7^{\mathrm{b}}$ & $94.5^{\mathrm{b}}$ & $96.3^{\mathrm{c}}$ & 0.39 & $<0.001$ & $<0.001$ & $<0.001$ \\
\hline Total $(\%)$ & $90.1^{\mathrm{a}}$ & $92.1^{\mathrm{b}}$ & $93.3^{\mathrm{bc}}$ & $94.2^{\mathrm{c}}$ & 0.40 & 0.002 & $<0.001$ & NS \\
\hline \multicolumn{9}{|l|}{ Rumen kinetics } \\
\hline Rumen pool (g) & 1.7 & 1.9 & 1.5 & 1.1 & 0.48 & NS & - & - \\
\hline $\mathrm{K}_{\mathrm{d}}^{6}\left(\mathrm{~h}^{-1}\right)$ & 0.4 & 0.4 & 0.5 & 0.5 & 0.27 & NS & - & - \\
\hline $\operatorname{MRT}^{7}(\mathrm{~h})$ & 16 & 34 & 42 & 44 & 14 & NS & - & - \\
\hline
\end{tabular}

${ }^{\mathrm{a}-\mathrm{c}}$ Means within a row with different superscripts differ $(P<0.05)$; NS when $P>0.10$

${ }^{1}$ Treatments: 23, 2,023, 3,982, and 6,015 phytase units (FTU) $/ \mathrm{kg}$ of DM for none, low, medium, and high. One FTU is the amount of enzyme that liberates $1 \mu \mathrm{mol}$ of inorganic phosphate per minute from $0.0051 \mathrm{M}$ Na-phytate at $\mathrm{pH} 5.5$ and $37^{\circ} \mathrm{C}$ (Engelen et al., 1994).

${ }^{2}$ Fixed effect of treatment.

${ }^{3}$ Linear and quadric orthogonal polynomial contrasts of treatment. Readers should only consider the pairwise comparisons or the linear and quadratic contrasts and not both.

${ }^{4}$ Based on analyses of individual feedstuffs.

${ }^{5}$ Based on analyses of TMR.

${ }^{6}$ Fractional rate of degradation.

${ }^{7}$ Mean retention time.

doses. The phytase activity was highest around $2 \mathrm{~h}$ after feeding at $1000 \mathrm{~h}$ (Figure 1).

\section{Phosphorus Partitioning}

No effect of treatment was found on $\mathrm{P}$ intake or flow to the duodenum, whereas flow of $\mathrm{P}$ to the ileum tended to increase $(P=0.082)$. Fecal $\mathrm{P}$ excretion increased $(P$ $=0.037)$ with exogenous phytase (Table 4$)$. Contents of $\mathrm{P}$ in urine, plasma, and milk were not affected by treatment. Flow of microbial $\mathrm{P}$ to the duodenum increased $(P=0.024)$ with exogenous phytase.

\section{Ruminal $\mathrm{pH}$ and Degradation of NDF}

Rumen degradability of NDF was not affected by treatment and averaged $68 \pm 0.6 \%$. Treatment did not affect average $\mathrm{pH}(5.8 \pm 0.03)$, and an effect of treatment was found in only 1 of the 12 sampling times (results not shown).

\section{DISCUSSION}

Cows in the present study had stable DMI during the experimental period. Milk yield and composition (fat and protein) were not affected by treatment or period. The experiment was designed to study degradation of inositol phosphate and the effect of exogenous phytase.
Therefore, feedstuffs with a low content of natural phytase were chosen, and a large amount of rapeseed cake was used in the TMR because of its high content of inositol phosphate (Eeckhout and De Paepe, 1994). However, because of this, the $\mathrm{P}$ content in the TMR $(3.8 \mathrm{~g}$ of $\mathrm{P} / \mathrm{kg}$ of $\mathrm{DM})$ was higher than the Danish recommendations (3.4 $\mathrm{g}$ of $\mathrm{P} / \mathrm{kg}$ of $\mathrm{DM}$; Nielsen and Volden, 2011), and reduced fecal $\mathrm{P}$ excretion was not expected as a treatment response.

\section{Intake of Inositol Phosphate}

The present study revealed that the TMR with exogenous phytase contained less total inositol phosphate $\mathrm{P}$ and $\mathrm{InsP}_{6}-\mathrm{P}$ than the control at the time of sampling. These findings indicate that the exogenous phytase already started working during mixing and feeding of the TMR. Samples of the TMR were taken approximately 2 to $3 \mathrm{~h}$ after the rations were mixed, but they were not taken at a specific time. Further investigations are therefore needed to determine the effect of exogenous phytase on the degradation of inositol phosphate in the TMR between mixing and time of ingestion.

\section{Degradation of Inositol Phosphate}

Ruminal and total-tract degradation of $\mathrm{InsP}_{6}$ were higher when exogenous phytase was added to the TMR. 
Table 4. Effect of phytase dose on flows of $\mathrm{P}$ and partitioning of $\mathrm{P}$

\begin{tabular}{|c|c|c|c|c|c|c|c|c|}
\hline Item & \multicolumn{4}{|c|}{ Treatment $^{1}$} & SEM & $\frac{P \text {-value }}{2}$ & \multicolumn{2}{|c|}{ Contrast $^{3}$ ( $P$-value $)$} \\
\hline \multicolumn{9}{|l|}{ Flow } \\
\hline Duodenum (g/d) & 108.7 & 113.0 & 115.7 & 111.2 & 3.81 & NS & - & - \\
\hline $\operatorname{Ileum}(\mathrm{g} / \mathrm{d})$ & 41.0 & 42.8 & 48.1 & 45.6 & 1.64 & 0.082 & 0.04 & NS \\
\hline Feces $(\mathrm{g} / \mathrm{d})$ & $45.6^{\mathrm{a}}$ & $51.0^{\mathrm{b}}$ & $52.1^{\mathrm{b}}$ & $49.8^{\mathrm{b}}$ & 1.21 & 0.037 & 0.047 & 0.019 \\
\hline Plasma P (mmol/L) & 1.9 & 2.0 & 1.9 & 2.0 & 0.04 & NS & - & - \\
\hline Duodenal flow of microbial P (g/d) & $49.0^{\mathrm{a}}$ & $57.4^{\mathrm{b}}$ & $53.3^{\mathrm{ab}}$ & $54.1^{\mathrm{b}}$ & 1.33 & 0.024 & NS & 0.03 \\
\hline
\end{tabular}

${ }^{\mathrm{a}-\mathrm{c}}$ Means within a row with different superscripts differ $(P<0.05)$; NS when $P>0.10$.

${ }^{1}$ Treatments: 23, 2,023, 3,982, and 6,015 phytase units (FTU)/kg of DM for none, low, medium, and high. One FTU is the amount of enzyme that liberates $1 \mu \mathrm{mol}$ of inorganic phosphate per minute from $0.0051 \mathrm{M}$ Na-phytate at $\mathrm{pH} 5.5$ and $37^{\circ} \mathrm{C}$ (Engelen et al., 1994).

${ }^{2}$ Fixed effect of treatment.

${ }^{3}$ Linear and quadric orthogonal polynomial contrasts of treatment. Readers should only consider the pairwise comparisons or the linear and quadratic contrasts and not both.

Degradation of $\operatorname{InsP}_{6}$ increased with dose of phytase but with a declining marginal effect of increasing the dose (Table 3).

The results of the present study confirm findings in previous studies (Knowlton et al., 2007; Sehested and
Lund, 2007). Sehested and Lund (2007) showed that exogenous phytase increased the rumen degradability of $\mathrm{InsP}_{6}$ from 79 to $84 \%$, and in the present study, the rumen degradabilities of $\mathrm{InsP}_{6}$ were found to be $86,94,94$, and $96 \%$ for none, low, medium, and high,

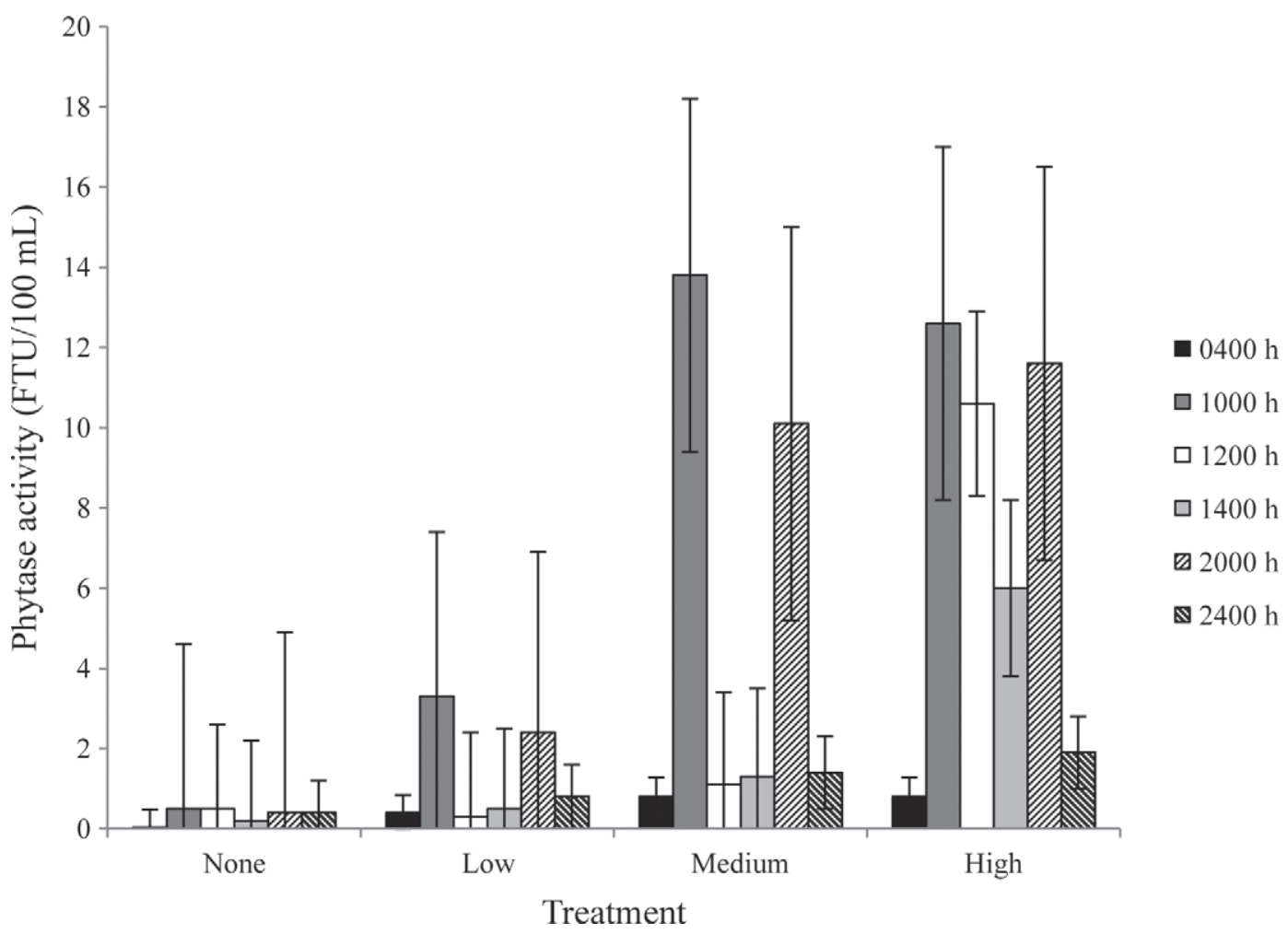

Figure 1. Phytase activity in rumen fluid (FTU/100 mL) at 6 different sampling times $(0400,1000,1200,1400,2000$, and 2400 h). Cows were fed at 0830 and $1730 \mathrm{~h}$. Treatments none, low, medium, and high correspond to 23, 2,023, 3,982, or 6,015 FTU/kg of DM. One FTU (phytase unit) is defined as the amount of enzyme that liberates $1 \mu \mathrm{mol}$ of inorganic phosphate per minute from a $0.0051 \mathrm{M} \mathrm{Na-phytate}$ solution at pH 5.5 and $37^{\circ} \mathrm{C}$ (Engelen et al., 1994). LSM and SEM for 4 determinations are shown. 
respectively. Sehested and Lund (2007) used a commercial phytase, and the dose was 1,900 FTU/kg of DM, which is comparable to the low dose $(2,023 \mathrm{FTU} / \mathrm{kg}$ of $\mathrm{DM}$ ) used in the present study. The present study verifies that endogenous microbial phytase activity in the rumen of lactating cows is limiting for degradation of inositol phosphate, because rumen degradation of $\operatorname{InsP}_{6}$ increased when exogenous phytase was added.

In the present study, $\mathrm{k}_{\mathrm{d}}$ and $\mathrm{MRT}$ for $\mathrm{InsP}_{6}-\mathrm{P}$ were not affected by treatment. The MRT for $\mathrm{InsP}_{6}-\mathrm{P}$ was expected to decrease when phytase was added, because rumen degradation of $\operatorname{Ins}_{6}-\mathrm{P}$ increased. The MRT is calculated based on rumen pool and duodenal flow of a given nutrient. The rumen pool of $\operatorname{Ins}_{6}-\mathrm{P}$ was found to be constant and independent of treatment, whereas the duodenal flow of $\mathrm{InsP}_{6}-\mathrm{P}$ decreased when phytase was added. This suggests the existence of a fraction of inositol phosphate that has a very low degradability in the rumen and that is unaffected by the phytase addition. This fraction appears to be retained in the rumen, which leads to a constant rumen pool of $\mathrm{InsP}_{6}-\mathrm{P}$. In the present study, the majority of the inositol phosphate $\mathrm{P}$ found in the TMR originated from rapeseed cake (98\%). Rapeseed cake contains a lot of shells, which could be expected to have low degradability and high MRT. In oilseeds (peanuts, sunflower seeds, and cottonseeds), the inositol phosphate is found in the kernel, whereas in soybean, inositol phosphate has no specific site of location (Erdman, 1979; Maga, 1982). Rapeseed cake may be similar to soybean, and therefore inositol phosphate $\mathrm{P}$ might be located in the shells as well as in the kernel of rapeseed. If inositol phosphate $\mathrm{P}$ is deposited in the shell of rapeseed, some of the inositol phosphate $\mathrm{P}$ may be selectively retained in the rumen, perhaps explaining why the rumen pool of $\mathrm{InsP}_{6}-\mathrm{P}$ was constant and independent of treatment, which, combined with the lower flow of $\operatorname{InsP}_{6}-\mathrm{P}$ to the duodenum, resulted in a high retention time for $\mathrm{InsP}_{6}-\mathrm{P}$ in the rumen in cows fed the exogenous phytase.

\section{Phytase in the Rumen}

In the present study, exogenous phytase led to a higher rumen pool of phytase compared with the control feed, indicating that the phytase activity in the rumen can be enhanced by adding phytase to the feed. The average phytase activity across sampling time during the day and in the rumen fluid sampled at $1000 \mathrm{~h}$ and $1200 \mathrm{~h}$ tended to be higher when the medium and high phytase doses were applied compared with the control and low doses. The phytase activity in the ruminal fluid was found to peak around $2.5 \mathrm{~h}$ after feeding.

\section{Phosphorus Partitioning}

As expected, no effect of treatment was found on total P intake or flow to the duodenum. We did, however, observe a tendency to increased flow of $\mathrm{P}$ to the ileum and increased $\mathrm{P}$ excretion with exogenous phytase. Hill et al. (2002) found no effect of exogenous phytase on fecal excretion of $\mathrm{P}$ when dairy cows were fed diets containing low or normal levels of inositol phosphate, whereas other researchers have shown that adding exogenous phytase reduced fecal excretion of $\mathrm{P}$ (Kincaid et al., 2005; Knowlton et al., 2007). Kincaid et al. (2005) found a tendency toward lower P excretion in cows fed phytase, whereas Knowlton et al. (2007) found that the addition of a cellulase-phytase blend reduced $P$ excretion in feces.

In the present study, flow of microbial $\mathrm{P}$ to the duodenum increased with exogenous phytase, and low digestibility of microbial P $(43 \% \pm 4.1$; Sehested et al., 2012) might explain the higher level of $P$ in the feces when phytase was added to the rations. The increased flow of microbial $\mathrm{P}$ to the duodenum might indicate increased microbial incorporation in the rumen with exogenous phytase.

As expected, $\mathrm{P}$ concentrations in urine, plasma, and milk were unaffected by treatment. On average, $\mathrm{P}$ concentration in milk was $0.94 \pm 0.09 \mathrm{~g} / \mathrm{kg}$ of milk and very similar to what has been found for Danish Holsteins in a previous study (0.98 to $1.06 \mathrm{~g}$ of $\mathrm{P} / \mathrm{kg}$ of milk; Hermansen et al., 2005).

\section{Ruminal $\mathrm{pH}$ and Degradation of NDF}

Ruminal degradation of NDF was close to what was expected. Overall, ruminal $\mathrm{pH}$ was not affected by treatment, and $\mathrm{pH}$ was affected by treatment at only one sampling time, which appears to be coincidental (data not shown). Optimum $\mathrm{pH}$ for the phytase used in the study was 5 to 5.5 , whereas $80 \%$ of relative activity remained in a $\mathrm{pH}$ range from 4.2 to 6.0 (BraskPedersen et al., 2011). In the present study, the average $\mathrm{pH}$ varied from 5.8 to 5.9 with a decrease in rumen $\mathrm{pH}$ after feeding.

\section{The Use of Phytase in Practice}

The present study showed that the availability of feed $\mathrm{P}$ can be increased due to enhanced degradation of inositol phosphate in the TMR and in the rumen when exogenous microbial phytase is added to the TMR. This implies that the content of $\mathrm{P}$ in the TMR might be reduced without compromising the requirements of the animal and the rumen microbes. On the other hand, the 
increased flow of microbial $\mathrm{P}$ to the duodenum when exogenous phytase is added to the feed could indicate that microbial incorporation of $\mathrm{P}$ in the rumen was limited by the availability of feed $\mathrm{P}$ when phytase was not added to the TMR, and thereby that the efficiency of ruminal metabolism might be compromised, even at $3.8 \mathrm{~g}$ of $\mathrm{P} / \mathrm{kg}$ of $\mathrm{DM}$ in a TMR with a high content of inositol phosphate.

As the excretion of $\mathrm{P}$ in manure is tightly linked to the intake of $\mathrm{P}$ (Morse et al., 1992b; Wu et al., 2000), possibilities may exist for reducing $\mathrm{P}$ excretion in manure if $\mathrm{P}$ content in feed is decreased. Phytase already started degrading inositol phosphate in the TMR, but further research is necessary to determine the effect of exogenous phytase in the feed before ingestion. Further research on this aspect should include the effect of incubation time, humidity, temperature, and timing of phytase addition relative to feeding the animals.

\section{CONCLUSIONS}

Rumen and total-tract degradation of inositol phosphate were increased when exogenous phytase was added to the TMR. Degradation of inositol phosphate occurred mainly before the duodenum. Degradation of inositol phosphate increased with dose of phytase, but increasing the dose had a declining marginal effect. Exogenous phytase led to a higher rumen pool of phytase. The exogenous phytase started degrading the inositol phosphate in the TMR before feeding, having an effect in the TMR and the rumen.

\section{ACKNOWLEDGMENTS}

We gratefully acknowledge Torkild Nyholm Jakobsen (Aarhus University, AU Foulum, Denmark) and Daisy Hilbrands (Novozymes A/S, Bagsvaerd, Denmark) for their skillful technical assistance, and Ulrich Halekoh (Aarhus University, AU Foulum, Denmark) for statistical assistance. Funding for the present study was provided by the Danish Food Industry Agency (no. 341208-02257), Novozymes A/S (Bagsvaerd, Denmark), and Faculty of Agricultural Sciences, Aarhus University (Tjele, Denmark).

\section{REFERENCES}

Allen, M. S., and D. R. Mertens. 1988. Evaluating constraints on fiber digestion by rumen microbes. J. Nutr. 118:261-270.

AOAC. 1990. Official Methods of Analysis. 15th ed. Association of Official Analytical Chemists, Washington, DC.

Blaabjerg, K., J. Hansen-Møller, and H. D. Poulsen. 2010. High-performance ion chromatography method for separation and quantification of inositol phosphates in diets and digesta. J. Chromatogr. B Analyt. Technol. Biomed. Life Sci. 878:347-354.
Brask-Pedersen, D. N., L. V. Glits $\varnothing$, L. K. Skov, P. Lund, and J. Sehested. 2011. Effect of exogenous phytase on feed inositol phosphate hydrolysis in an in vitro rumen fluid buffer system. J. Dairy Sci. 94:951-959.

Bravo, D., F. Meschy, C. Bogaert, and D. Sauvant. 2000. Ruminal phosphorus availability from several feedstuffs measured by the nylon bag technique. Reprod. Nutr. Dev. 40:149-162.

Bravo, D., F. Meschy, C. Bogaert, and D. Sauvant. 2002. Effects of fungal phytase addition, formaldehyde treatment and dietary concentrate content on ruminal phosphorus availability. Anim. Feed Sci. Technol. 99:73-95.

Carlsson, N. G., E. L. Bergman, E. Skoglund, K. Hasselblad, and A. S. Sandberg. 2001. Rapid analysis of inositol phosphates. J. Agric. Food Chem. 49:1695-1701.

Clark, W. D., J. E. Wohlt, R. L. Gilbreath, and P. K. Zajac. 1986. Phytate phosphorus intake and disappearance in the gastrointestinal tract of high-producing dairy cows. J. Dairy Sci. 69:3151-3155.

Dou, Z., J. D. Ferguson, J. Fiorini, J. D. Toth, S. M. Alexander, L. E. Chase, C. M. Ryan, K. F. Knowlton, R. A. Kohn, A. B. Peterson, J. T. Sims, and Z. Wu. 2003. Phosphorus feeding levels and critical control points on dairy farms. J. Dairy Sci. 86:3787-3795.

Eeckhout, W., and M. De Paepe. 1994. Total phosphorus, phytatephosphorus and phytase activity in plant feedstuffs. Anim. Feed Sci. Technol. 47:19-29.

Engelen, A. J., F. C. Van Der Heeft, P. H. G. Randsdorp, and E. L. C. Smit. 1994. Simple and rapid determination of phytase activity. J. AOAC Int. 77:760-764.

Erdman, J. W. 1979. Oilseed phytates: Nutritional implications. J. Am. Oil Chem. Soc. 56:736-741.

Godoy, S., C. Chicco, F. Meschy, and F. Requena. 2005. Phytic phosphorus and phytase activity of animal feed ingredients. Interciencia 30:24-28.

Hansen, B. 1989. Determination of nitrogen as elementary-N, an alternative to Kjeldahl. Acta Agric. Scand. 39:113-118.

Hermansen, J. E., J. H. Badsberg, T. Kristensen, and V. Gundersen. 2005. Major and trace elements in organically or conventionally produced milk. J. Dairy Res. 72:362-368.

Hill, B. E., S. L. Hankins, J. F. Kearney, J. D. Arseneau, D. T. Kelly, S. S. Donkin, B. T. Richert, and A. L. Sutton. 2002. Effects of feeding low phytic acid corn and phytase on phosphorus balance in lactating dairy cows. J. Dairy Sci. 85(Suppl. 1):44. (Abstr.)

Irving, G. 1980. Phytase. Pages 85-98 in Inositol Phosphates, Their Chemistry, Biochemistry and Physiology. D. J. Cosgrove, ed. Elsevier Scientific, Amsterdam, the Netherlands.

Kincaid, R. L., D. K. Garikipati, T. D. Nennich, and J. H. Harrison. 2005. Effect of grain source and exogenous phytase on phosphorus digestibility in dairy cows. J. Dairy Sci. 88:2893-2902.

Knowlton, K. F., C. M. Parsons, C. Cobb, and K. F. Wilson. 2005. Exogenous phytase plus cellulase and phosphorus excretion in lactating dairy cows. Prof. Anim. Sci. 21:212-216.

Knowlton, K. F., J. S. Radcliffe, C. L. Novak, and D. A. Emmerson. 2004. Animal management to reduce phosphorus losses to the environment. J. Anim Sci. 82(E-Suppl.):E173-E195.

Knowlton, K. F., M. S. Taylor, S. R. Hill, C. Cobb, and K. F. Wilson. 2007. Manure nutrient excretion by lactating cows fed exogenous phytase and cellulase. J. Dairy Sci. 90:4356-4360.

Konishi, C., T. Matsui, W. Park, H. Yano, and F. Yano. 1999. Heat treatment of soybean meal and rapeseed meal suppresses rumen degradation of phytate phosphorus in sheep. Anim. Feed Sci. Technol. 80:115-122.

Maga, J. A. 1982. Phytate: Its chemistry, occurrence, food interactions, nutritional significance, and methods of analysis. J. Agric. Food Chem. 30:1295-1319.

Mertens, D. R. 2002. Gravimetric determination of amylase-treated neutral detergent fiber in feeds with refluxing in beakers or crucibles: Collaborative study. J. AOAC 85:1217-1240.

Morse, D., H. H. Head, and C. J. Wilcox. 1992a. Disappearance of phosphorus in phytate from concentrates in vitro and from rations fed to lactating dairy cows. J. Dairy Sci. 75:1979-1986.

Morse, D., H. H. Head, C. J. Wilcox, H. H. Van Horn, C. D. Hissem, and B. Harris Jr.. 1992b. Effects of concentration of dietary phos- 
phorus on amount and route of excretion. J. Dairy Sci. 75:3039 3049 .

Motomizu, S., T. Wakimoto, and K. Toei. 1983. Spectrofotometric determination of phosphate in river waters with molybdate and malachite green. Analyst (Lond.) 108:361-367.

Nelson, T. S., L. B. Daniels, J. R. Hall, and L. G. Shields. 1976. Hydrolysis of natural phytate phosphorus in the digestive tract of calves. J. Anim. Sci. 42:1509-1512.

Nelson, T. S., L. W. Ferrara, and N. L. Storer. 1968. Phytate phosphorus content of feed ingredients derived from plants. Poult. Sci. 47:1372-1374.

Nielsen, N. I., and H. Volden. 2011. Animal requirements and recommendations. Pages 85-111 in NorFor-The Nordic Feed Evaluation System. EAAP publication No. 130. H. Volden, ed. Wageningen Academic Publishers, Wageningen, the Netherlands.

Park, W., T. Matsui, C. Konishi, S. Kim, F. Yano, and H. Yano. 1999. Formaldehyde treatment suppresses ruminal degradation of phytate in soybean meal and rapeseed meal. Br. J. Nutr. 81:467-471.

Pontoppidan, K., D. Pettersson, and A. S. Sandberg. 2007. Peniophora lycii phytase is stable and degrades phytate and solubilises minerals in vitro during simulation of gastrointestinal digestion in the pig. J. Sci. Food Agric. 87:2700-2708.

Schürch, A. F., L. E. Lloyd, and E. W. Crampton. 1950. The use of chromic oxide as an index for determining the digestibility of a diet. J. Nutr. 41:629-636.

Sehested, J., and P. Lund. 2007. Ruminal degradation of inositol bound $\mathrm{P}$ is affected by feed composition and external phytase. Page 328 in Book of Abstracts No. 13 (2007), 58th Annu. Mtg. Eur. Assoc. Anim. Prod., Dublin, Ireland. Wageningen Academic Publishers, Wageningen, the Netherlands.

Sehested, J., P. Lund, and H. Jørgensen. 2012. Intestinal digestibility of phosphate from ruminal microbes. Page 157 in Book of Abstracts No. 18 (2012), 63rd Annu. Mtg. Eur. Assoc. Anim. Prod.,
Bratislava, Slovakia. Wageningen Academic Publishers, Wageningen, the Netherlands.

Sharpley, A. N., and P. J. A. Winthers. 1994. The environmentallysound management of agricultural phosphorus. Fert. Res. 39:133146. (Abstr.)

Skoglund, E., N. G. Carlsson, and A. S. Sandberg. 1997. Determination of isomers of inositol mono- to hexaphosphates in selected foods and intestinal contents using high-performance ion chromatography. J. Agric. Food Chem. 45:431-436.

Snedecor, G. W., and W. G. Cochran. 1967. One-way classifications, analysis of variance. Pages 258-298 in Statistical Methods. 6th ed. The Iowa State University Press, Ames.

Stoldt, W. 1952. Vorslag zur Vereinheitlichung der Fettbestimmung in Lebensmitteln. Fette und Seifen 54:206-207.

Stuffins, C. B. 1967. The determination of phosphate and calcium in feeding stuffs. Analyst 92:107-111.

Tilley, J. M. A., and R. A. Terry. 1963. A two-stage technique for the in vitro digestion of forage crops. J. Br. Grassl. Soc. 18:104-111.

Viveros, A., C. Centeno, A. Brenes, R. Canales, and A. Lozano. 2000. Phytase and acid phosphatase activities in plant feedstuffs. J. Agric. Food Chem. 48:4009-4013.

Weisbjerg, M., and T. Hvelplund. 1993. Bestemmelse af nettoenergiindhold (FEk) i foder til kvæg. Pages 3-39 in Research Report No. 3 (1993), Statens husdyrbrugsforsøg, Foulum. Research Centre Foulum, University of Aarhus, Tjele, Denmark.

Wodzinski, R. J., and A. H. J. Ullah. 1996. Phytase. Adv. Appl. Microbiol. 42:263-302.

Wu, Z., L. D. Satter, and R. Sojo. 2000. Milk production, reproductive performance, and fecal excretion of phosphorus by dairy cows fed three amounts of phosphorus. J. Dairy Sci. 83:1028-1041.

Zinn, R. A., and F. N. Owens. 1986. A rapid procedure for purine measurement and its use for estimating net ruminal protein synthesis. Can. J. Anim. Sci. 66:157-166. 